Journal of Engineering and Applied Sciences 14 (17): 6385-6391, 2019

ISSN: 1816-949X

(C) Medwell Journals, 2019

\title{
Harmonic Filter for Microgrid Based on Extreme Learning Machine
}

\author{
${ }^{1}$ Mat Syai' in, ${ }^{2}$ D.K. Setiawan, ${ }^{3}$ N.H. Rohiem, ${ }^{3}$ M.F. Adiatmoko, ${ }^{3}$ Adi Soeprijanto and ${ }^{4}$ A.M. Hatta \\ ${ }^{1}$ Study Program of Automation Engineering, \\ Shipbuilding Institute of Polytechnic Surabaya (SHIPS/PPNS), Surabaya, Indonesia \\ ${ }^{2}$ Department of Electrical Engineering, Universitas of Jember, Jember, Indonesia \\ ${ }^{3}$ Department of Electrical Engineering, \\ ${ }^{4}$ Department of Engineering Physics, Institute Teknologi Sepuluh Nopember (ITS) Surabaya, \\ Surabaya, Indonesia \\ matt.syaiin@ppns.ac.id, masdedyks@gmail.com, nasyithhananur@gmail.com, \\ fajar.moko@gmail.com, adisup@ee.its.ac.id, amhatta@ep.its.ac.id
}

\begin{abstract}
The development of converter technology has made the price of renewable energy-based power plants more affordable. The increasing number of renewable energy-based power plants has a positive impact but also has a negative impact. One of the negative impacts that occur in renewable energy-based power plants is the emergence of harmonics. Harmonics in principle cannot be removed from the electric power system but harmonics can be controlled in order to minimize the negative impact. This research is developing active filter based on Extreme Learning Machine (ELM) concept. ELM is used as control strategies to produces signals opposite with harmonic signals. From the simulation results shown that the active filter based on ELM can reduce the Total Harmonic Distortion (THD) in microgrid systems effectively.
\end{abstract}

Key words: Converter, active filter, extreme learning machine, total harmonic distortion, microgrid, plants

\section{INTRODUCTION}

Development of digital technology in electrical systems, making significant changes to the characteristics of electric power systems. The most significant influence is indicated by the use of converter technology. Excessive use of the converter can change the nature of the electrical signal from a pure sinus to a distorted sinus (Chakir et al., 2014; Anwar et al., 2015; Hashempour et al., 2016; Gonzatti et al., 2017). The development of converter technology which is getting cheaper, makes the use of renewable energy-based power plants increase. Its use is also combined with conventional generators which are commonly known as micro grid systems (Abdelsalam et al., 2011; Li et al., 2016; Cao et al., 2018; Feng et al., 2018). This is intended to improve efficiency, reduce environmental pollution and preserve nature (Dudurych et al., 2012). Microgrid systems have a very positive impact on the electric power system. However, microgrids also cause negative impacts such as harmonics. Harmonics can be systemically detrimental if not well controlled (Setiawan et al., 2015).

At present, many researchers have developed filter technology to reduce the negative effects of harmonics, both passive and active filters. The advantage of passive filters is the relatively cheaper price but passive filter applications only function effectively at a constant load. While for active filters (Setiawan et al., 2015) the price is still expensive but its use can be widely applied in various loading conditions.

In this research, developed an active filter with employing abc-dq transformation (Setiawan et al., 2015). The advantage of using dq frame is the signal easier for controlling because the value in $\mathrm{dq}$ frame is not influenced by time. Which is very different with value in abc frame that changing by the time.

In this study, Extreme Learning Machine (ELM) controller is examined to replace the PI controller for controlling the active powwer filter. Simulation is performed in MATLAB after training ELM and it is shown that results are acceptable and applicable in gris system. The ELM controller can be less complicated and less costly to implement in industrial control applications as compared to PI controller (Setiawan et al., 2009).

\section{MATERIALS AND METHODS}

This study is employing dq frame concept to modify signals and implement it as main controller of an active

Corresponding Author: Mat Syai 'in, Study Program of Automation Engineering,

Shipbuilding Institute of Polytechic Surabaya (SHIPS/PPNS), Surabaya, Indonesia, matt.syaiin@ppns.ac.id 
filter. There are two kind of an active filter was design in this study, the first is an active filter based on PI (Proportional Integral) controller and the second is an active filter based on ELM (Extreme Learning Machine) controller. The detail process design can be expalin in the the flow chart as follow (Fig. 1).

Modeling of microgrid systems: Modeling of micro grid system in this study is employing MATLAB Simulink.

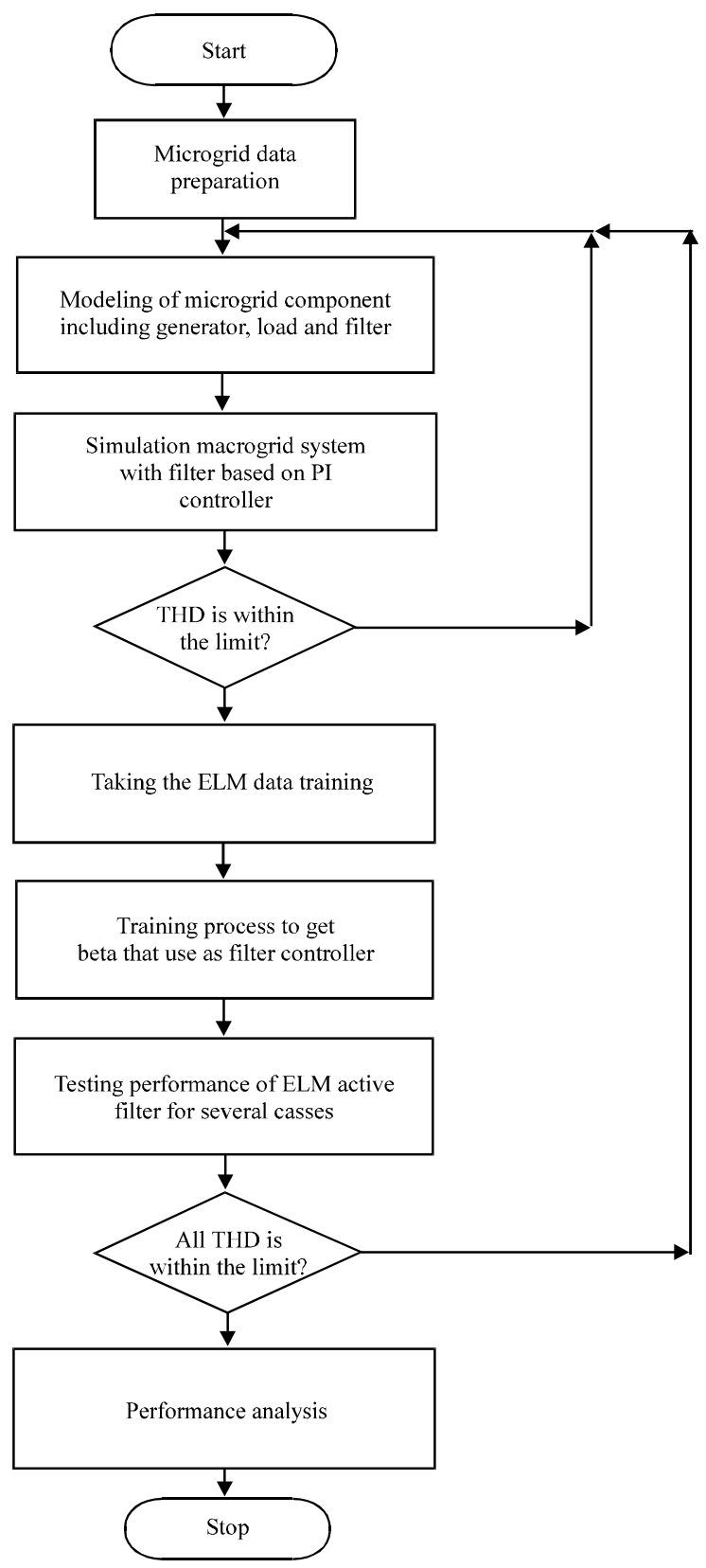

Fig. 1: Flowchart of the filter design
The micro grid model used in this simulation has three kinds of power plant. The first is diesel power plant. The second is direct solar system power plant and the third is battery with inverter. The models for those three kinds of power plants are explained in Fig. 2- 4.

Diesel power plant model: Diesel Power Plant (DPP) Model are derived from Synchronous Generator (SG)

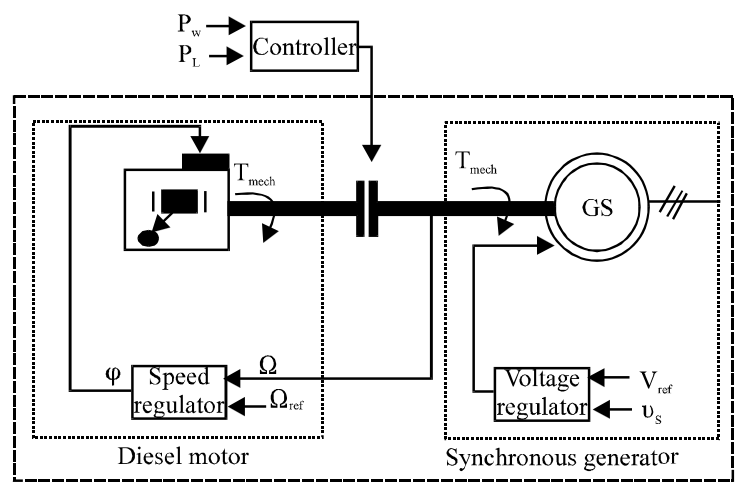

Fig. 2: DPP Model

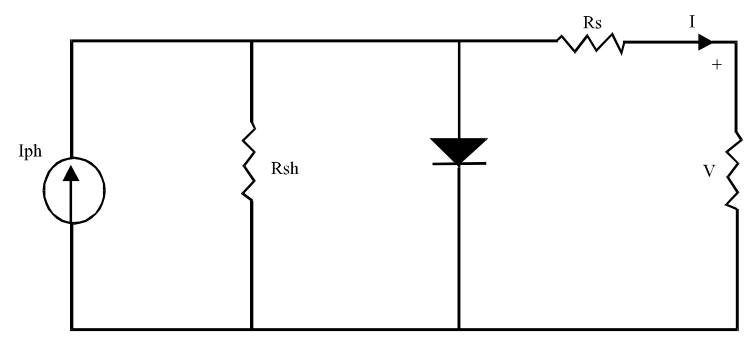

Fig. 3: PV equivalent circuit

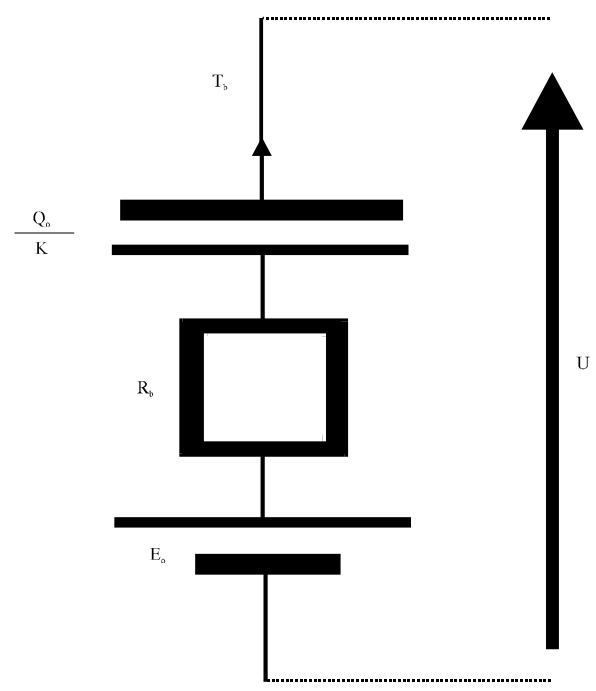

Fig. 4: Electrical equivalent model of the battery 


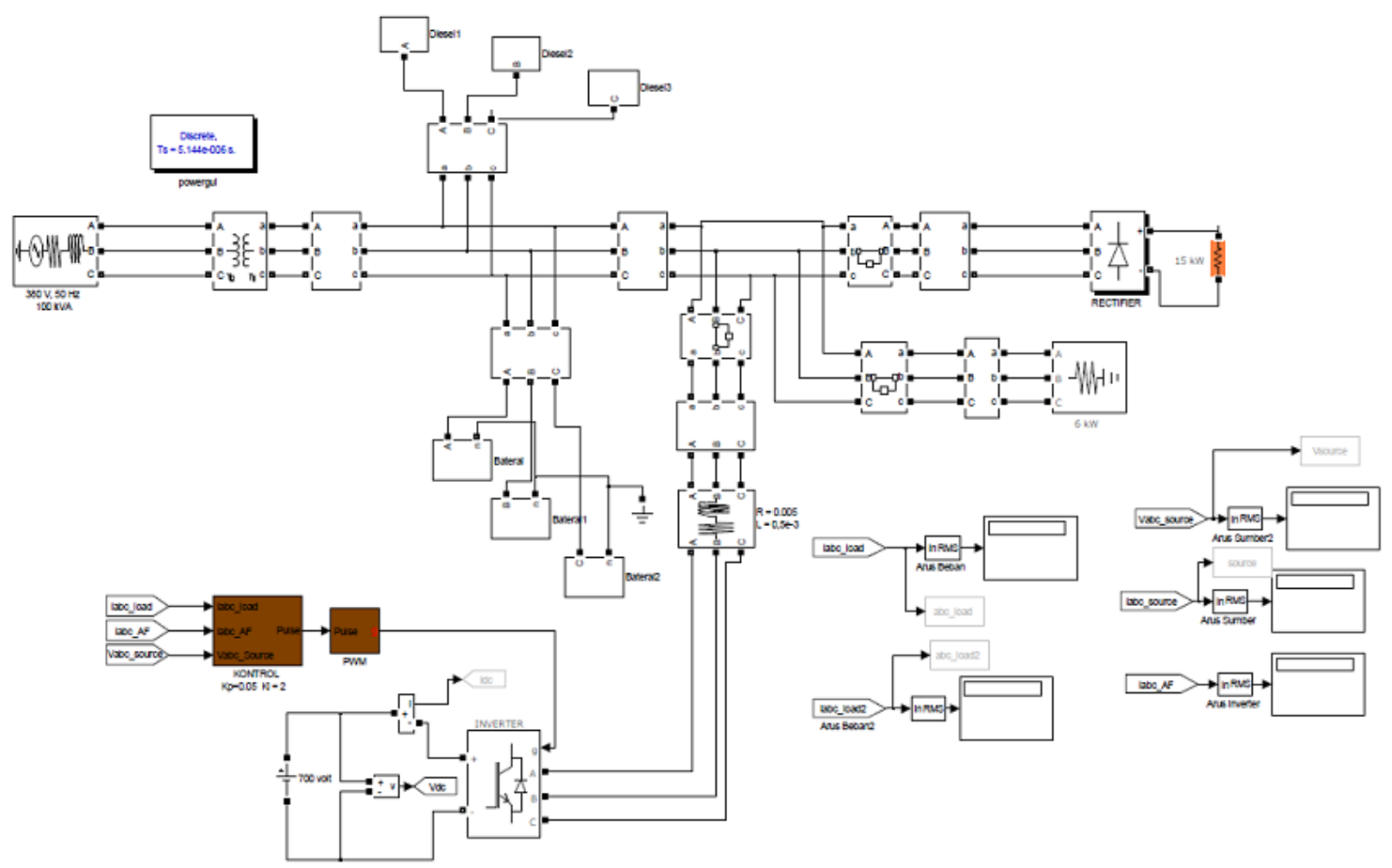

Fig. 5: The complete model of micro grid system simulation

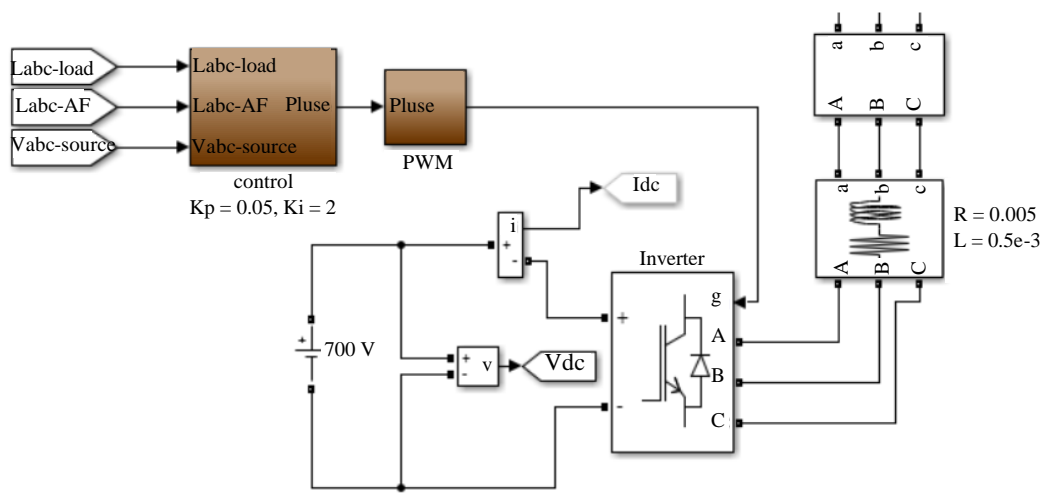

Fig. 6: Model of active harmonic filter

Model with prime mover couple to diesel engine. The complete model of DPP including controller models is shown in Fig. 2.

Solar systems power plant model: Solar systems power plant generates power by utilizing solar radiation and ambient temperature. The equivalent electrical circuit describing the solar cells array used in the analysis is shown in Fig. 3.

Modeling of battery storage system: The equivalent circuit of the batterystorage system can be represented as in Fig. 4. In this simulation, besides power plant model, a load model and filter model are also needed. The type of load tested in this simulation is a type of rectifier load which is intended to determine the level of harmonics on the micro grid. This simulation refers to IEEE 519-2014 for measuring and justifies the harmonic level. The complete model of simulation can be seen in Fig. 5 .

Modeling of harmonic filter: In general, there are two stages in the design process of ELM-based active filters. The first stage, an active filter is designed based on the PI controller and then the results of the control action from the PI-based active filter are used as training data by ELM to obtain a beta value that represents the relationship between input and output. The model of active filter based on PI controller can be seen in Fig. 6 and 7 . 


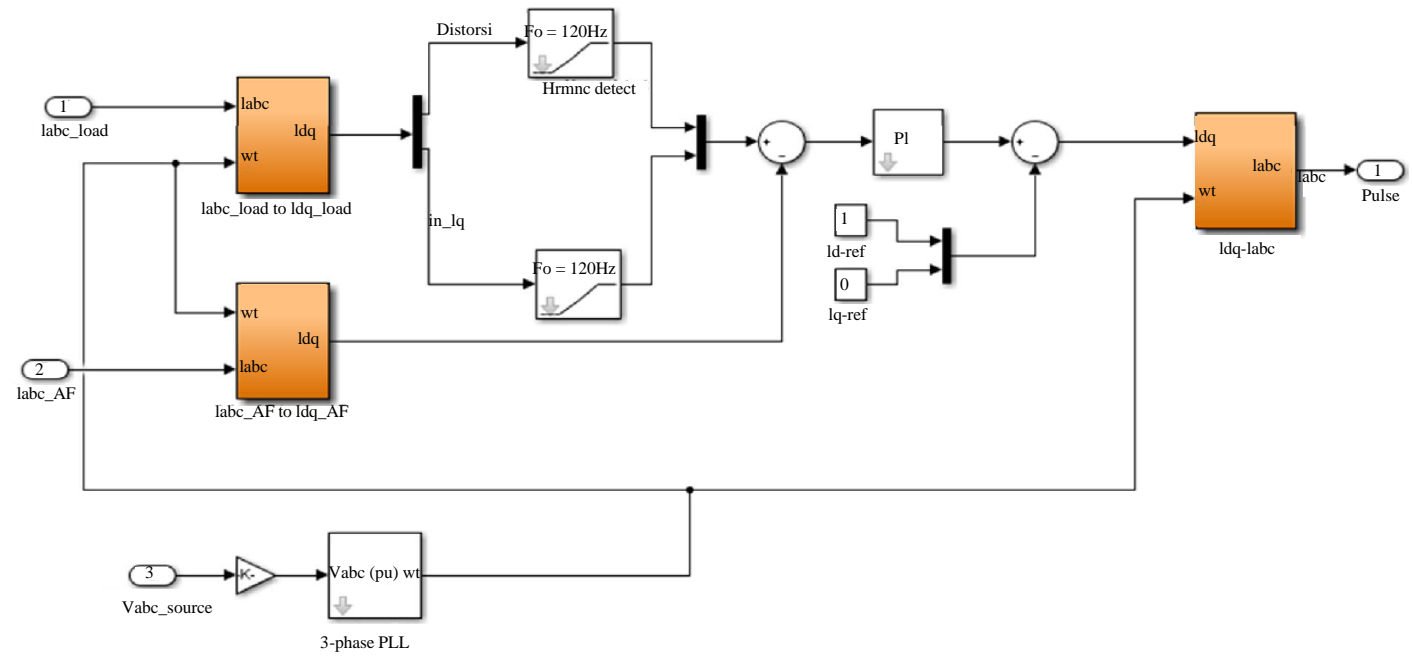

Fig. 7: Model of Proportional Integral (PI) controller for active harmonic filter

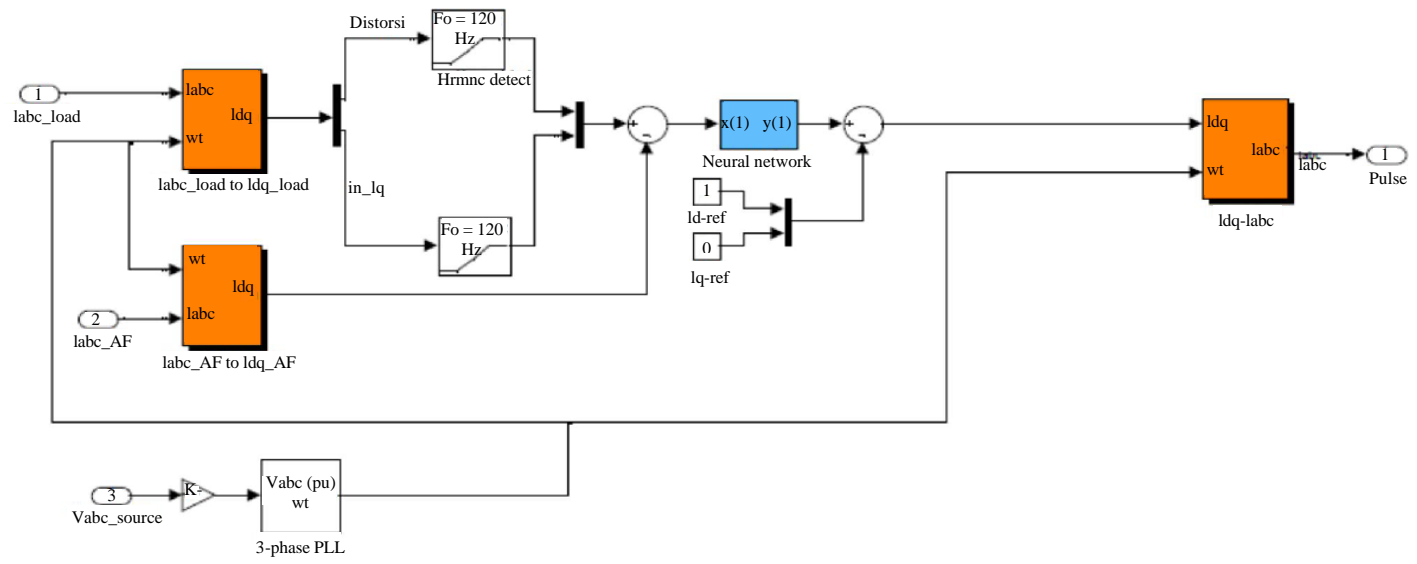

Fig. 8: Model of extreme learning machine controller for active harmonic filter

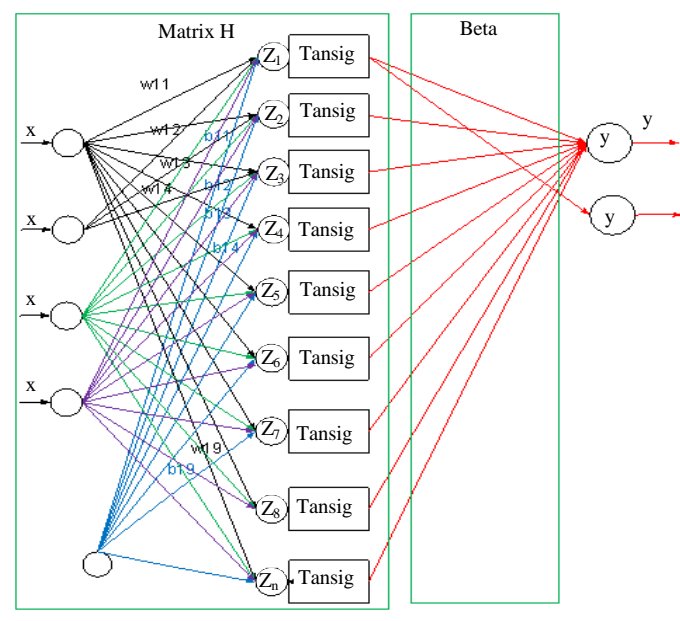

Fig. 9: Model of extreme learning machine
Harmonic active filter based on PI controller: Harmonic active filter based on extreme learning machine: Structure of ELM used in this simulation has four inputs and two outputs. The inputs are load voltages/currents in d-q frame and APF (Active Power Filter) voltages/currents in $\mathrm{d}-\mathrm{q}$ frame. The general model of ELM can be seen in Fig. 9.

After the training process is complete, the value obtained is a beta value that represents the relationship between input and output. The beta value is then integrated with the Simulink Model as shown in Fig. 7.

\section{RESULTS AND DISCUSSION}

Experiment and data analysis: In this study, performance verification of an active filter was carried out on three 


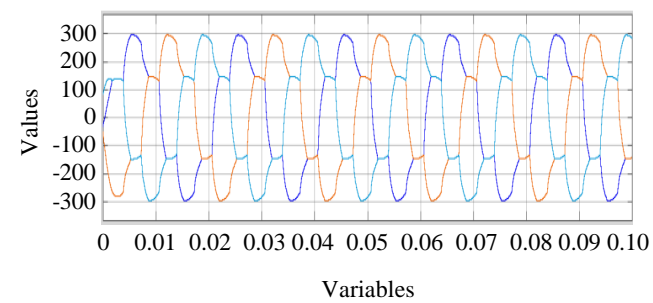

Fig. 10: The original voltage signals without controller
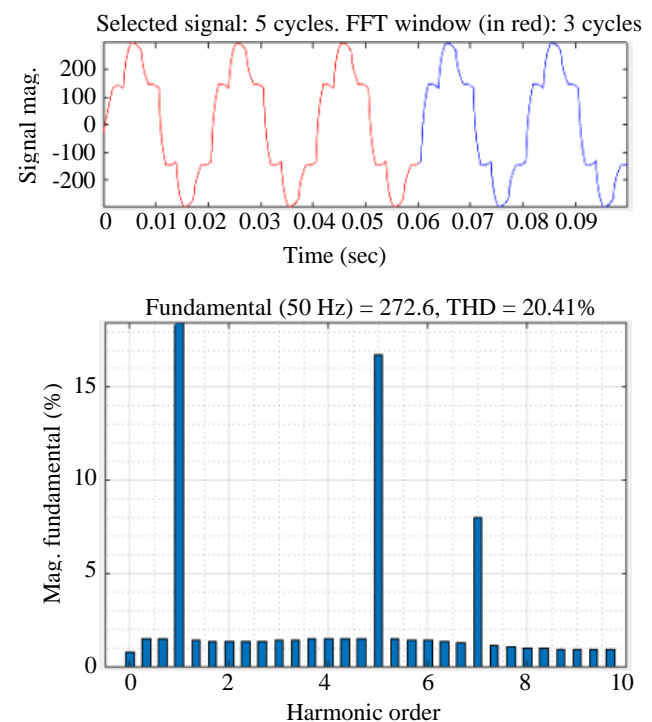

Fig. 11: THD analysis of voltage signals without controller: a) Signal and b) FFT analysis

stages testing for current and voltage parameters. The testing i.e., without controller with the PI controller and with the ELM controller.

Voltage parameter simulation: The simulation carried out at this stage utilizes a three phase voltage signal as shown in Fig.10. Figure 10 it is known that the voltage signal is distorted whichis characterized by an imperfect sinus signal. To determine the level of distortion from voltage harmonics, the voltage signal is processed by FFT (Fast Fourier Transformation). And the result can be seen in the Fig. 11.

Figure 11 it is known that the voltage THD is $20.41 \%$ which is categorized as exceeding the standard. To reduce the voltage THD, the PI controller based on active filter is simulated, the results of which can be seen in Fig. 12 and 13. Then compared with the simulation results using the active filter based on ELM controller, the results can be seen in Fig. 14 and 15.

Figure 12 and 13 it is known that the voltage THD level has decreased. This is indicated by a signal that is

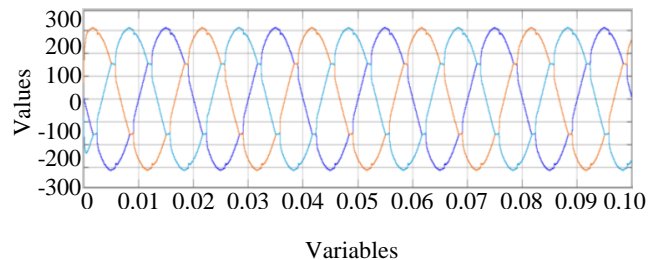

Fig. 12: The original voltage signals with PI controller
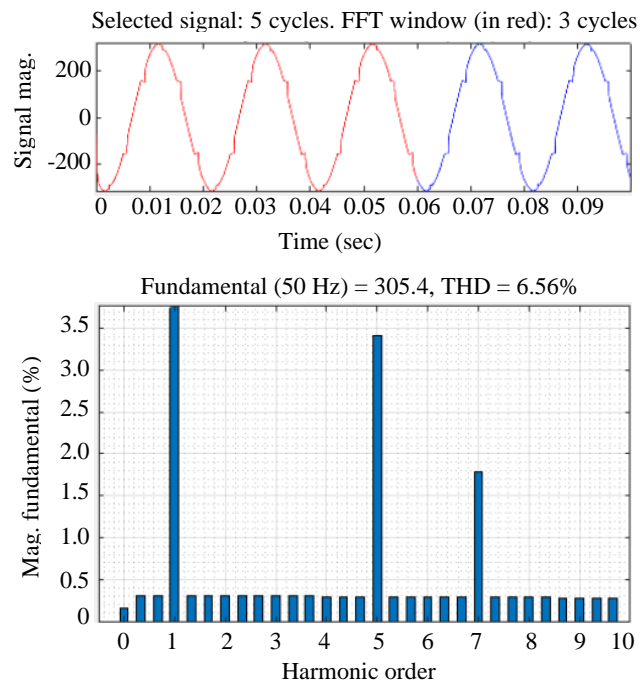

Fig. 13: THD analysis of voltage signals with PI controller: a) Signal and b) FFT analysis

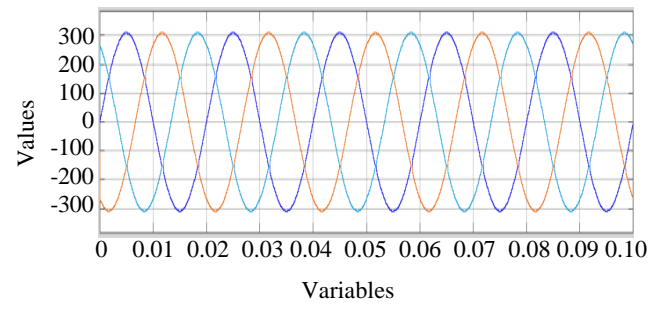

Fig. 14: The original voltage signals with ELM controller

closer to the pure sine signal. But the voltage THD that occurs is still more than $5 \%$ which is $6.56 \%$ which means it is still more than the permitted standard.

While the results shown in Fig. 14 and 15 which are simulations of the use of ELM-based active filters are known that the voltage THD level has a significant decrease of $1.05 \%$ which is in accordance with the allowed standard.

Current parameter simulation: To test the effectiveness of an active filters based on PI controllers and active filters based on ELM controllers, the simulation results are shown in Fig. 16-21. 

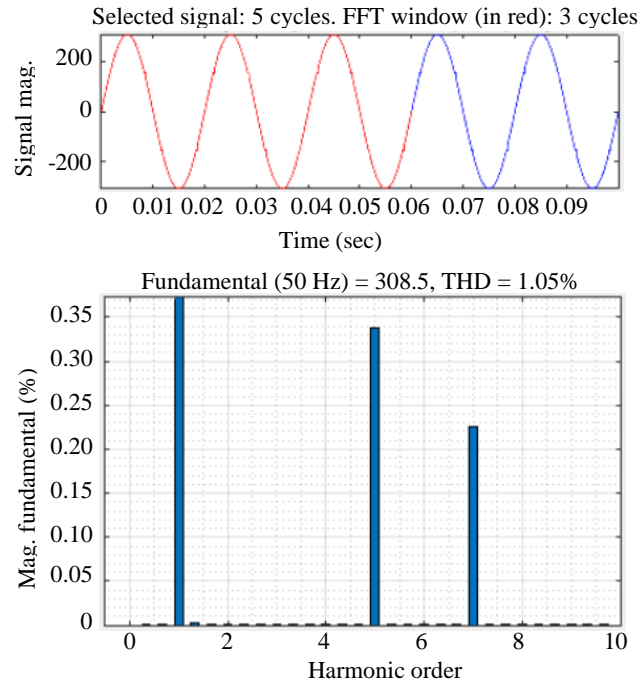

Fig. 15: THD analysis of voltage signals with ELM controller: a) Signal and b) FFT analysis

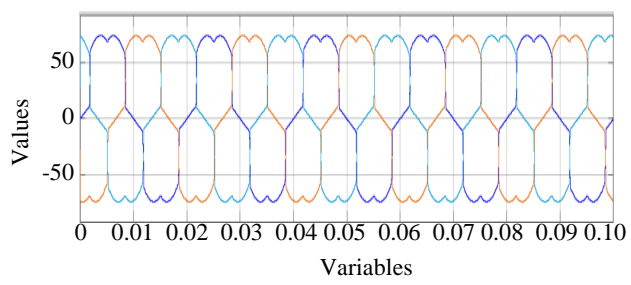

Fig. 16: The original current signals without controller
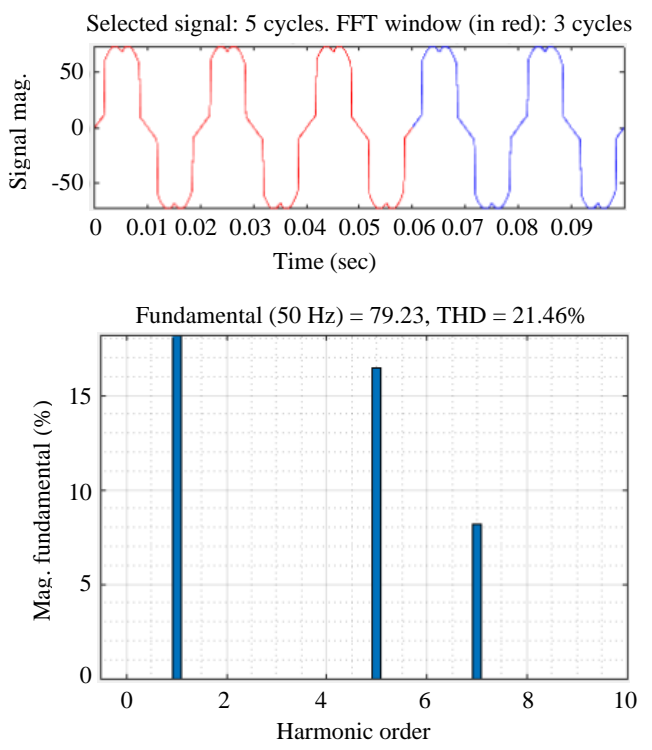

Fig. 17: THD analysis of voltage signals without controller: a) Signal and b) FFT analysis

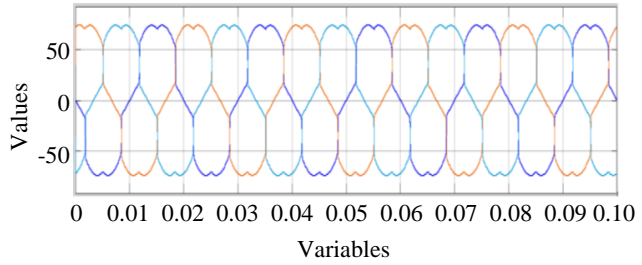

Fig. 18: The original current signals with PI controller
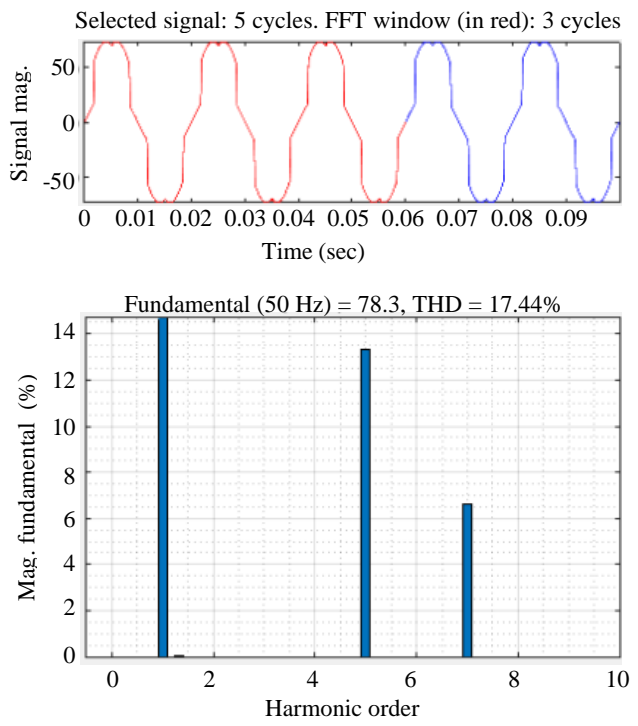

Fig. 19: THD analysis of current signals with PI controller: a) Signal and b) FFT analysis

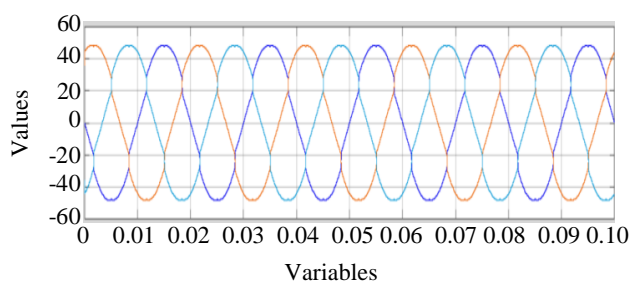

Fig. 20: The original current signals with ELM controller

Figures 16 and 17 show the simulation results without using a controller. From these results it is known that the current THD that exceeds the limit required by the IEEE standard is equal to $21.45 \%$. While the simulation results from the active filter based on PI controller, the results are presented in Fig. 18 and 19. From the two figures can be seen that the current THD has decreased but the results still exceed the permitted standard of $17.44 \%$. While the simulation results from the active filter based on ELM controller, the results are presented in Fig. 20 and 21. From the two figures can be seen that the current THD has decreased but the results still exceed the permitted standard of $6.96 \%$. 

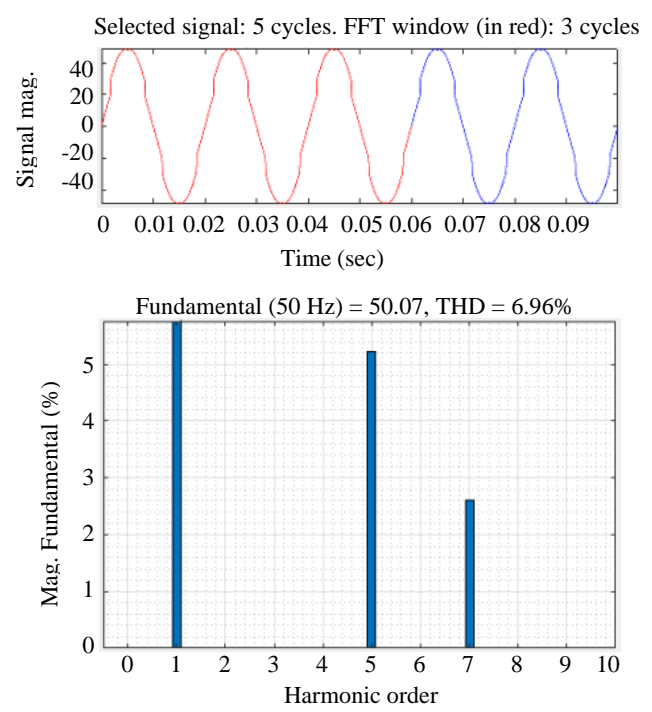

Fig. 21: THD analysis of current signals with ELM controller: a) Signal and b) FFT analysis

\section{CONCLUSION}

From the simulation results provided in section 3 can be concluded that the proposed method, abc-dq frame transformation and ELM controller of active harmonic filter is having beter performance comparing to PI controller of active harmonic filter. In the voltagee cases the PI controller can reduce $\mathrm{THD}$ until $6.56 \%$ while $\mathrm{NN}$ controller can reduce until $1.05 \%$. In other hand in the currents cases the PI controller can reduce THD current until $17.44 \%$ while the ELM controller can reduce until $6.96 \%$. According to these data, the proposed method is recomended as method for reducing $\mathrm{THD}$ either THD voltage or THD current.

\section{ACKNOWLEDGEMENT}

The researchers would like to sincerely thank the The Ministry of Research, Technology and Higher Education, Indonesia for financially supporting this research.

\section{REFERENCES}

Abdelsalam, A.K., A.M. Massoud, S. Ahmed and P.N. Enjeti, 2011. High-performance adaptive perturb and observe MPPT technique for photovoltaic-based microgrids. IEEE. Trans. Power Electron., 26: 1010-1021.
Anwar, S., A. Elrayyah and Y. Sozer, 2015. Efficient single-phase harmonics elimination method for microgrid operations. IEEE. Trans. Ind. Appl., 51: 3394-3403.

Cao, X., J. Zhang and H.V. Poor, 2018. Joint energy procurement and demand response towards optimal deployment of renewables. IEEE. J. Sel. Top. Signal Process., 12: 657-672.

Chakir, M., I. Kamwa and H. Le Huy, 2014. Extended C37. 118.1 PMU algorithms for joint tracking of fundamental and harmonic phasors in stressed power systems and microgrids. IEEE. Trans. Power Delivery, 29: 1465-1480.

Dudurych, I.M., A. Rogers, R. Aherne, L. Wang and F. Howell et al., 2012. Safety in numbers: Online security analysis of power grids with high wind pentration. IEEE. Power Energy Magaz., 10: 62-70.

Feng, J., B. Zeng, D. Zhao, G. Wu and Z. Liu et al., 2018. Evaluating demand response impacts on capacity credit of renewable distributed generation in smart distribution systems. IEEE. Access, 6: 14307-14317.

Gonzatti, R.B., S.C. Ferreira, C.H. da Silva, R.R. Pereira and L.E.B. da Silva et al., 2017. Using smart impedance to transform high impedance microgrid in a quasi-infinite busbar. IEEE. Trans. Smart Grid, 8: 428-436.

Hashempour, M.M., M. Savaghebi, J.C. Vasquez and J.M. Guerrero, 2016. A control architecture to coordinate distributed generators and active power filters coexisting in a microgrid. IEEE. Trans. Smart Grid, 7: 2325-2336.

Li, J., F. Li, X. Li, H. Liu and F. Chen et al., 2016. S-shaped droop control method with secondary frequency characteristics for inverters in microgrid. IET. Gener. Trans. Distrib., 10: 3385-3392.

Setiawan, D.K., M. Ashari and M.H. Purnomo, 2009. Diagonal recurrent neural network control of four-leg inverter for hybrid power system under fluctuating unbalanced loads. Proceedings of the 3rd International Student Conference on Advanced Science and Technology (ICAST), April 10-12, 2009, Seoul, Korea, pp: 1-2.

Setiawan, D.K., Y. Megantara and B.N. Syah, 2015. Three phase inverter of UPS control system for harmonic compensator and power factor correction using modified synchronous reference frame. Proceedings of the 2015 International Symposium on Electronics (IES), September 29-30, 2015, IEEE, Surabaya, Indonesia, ISBN:978-1-4673-9344-7, pp: 15-19. 